\title{
Performance Based Time History Analysis of Five Story Shear Frame Building Using MATLAB and ETABS
}

\author{
Ahmed S. Brwa ${ }^{1} \&$ Twana Ahmed Hussein ${ }^{2} \&$ Barham Haydar $^{3} \&$ Siva Kumar ${ }^{4}$ \\ ${ }^{1,2,3 \& 4}$ Department of Civil Engineering, Faculty of Engineering, Tishk International University, Erbil, \\ Iraq \\ Correspondence: Ahmed S. Brwa, Tishk International University, Erbil, Iraq. \\ Email: brwa.ahmed@tiu.edu.iq
}

Doi: 10.23918/eajse.v6i1p184

\begin{abstract}
This paper compares the time history analysis results for state space representation (SSR) method using MATLAB with the result conducted using ETABS. The equation of motion of the structure subjected to seismic excitation represented by second-order linear non-homogeneous differential equation. This equation reduced to two coupled first order differential equations and state space representation was formulated to represent the system in matrix form and MATLAB Simulink was used to determine response of the structure. The objectives of this study are i) to conduct a comparative study between the state space representation which is a powerful tool with results of ETABS. ii) to investigate the accuracy of SSR method. iii) to conduct a performance based dynamic analysis for shear frame structures and study outcome responses of the structure. This analysis was based on the assumptions, i) the total story mass is lumped at the center of story diaphragm. ii) No deflection occurs in beams; story beams are infinitely rigid in comparison to story columns. iii) no changes in the nature of the boundary conditions during and after the analysis iv) the system is elastic linear time-invariant (ELTI) and material nonlinearity is not considered. So that that structural degree of freedom decreased to be equivalent to the number of storys. The results showed a significant similarity in comparison with ETABS software. The maximum absolute difference of displacement and story drift ratio was $3.35 \mathrm{~mm}$ and 0.0016 was obtained at the roof of third and fifth story respectively.
\end{abstract}

Keywords: State Space Representative, Time History Analysis, Shear Frame, Dynamic Analysis, Linear Time-Invariant Systems, MATLAB, ETABS

\section{Introduction}

Time history analysis is very efficient performance-based analysis for special and high-rise buildings. It's required for structures located in high seismic zones to ensure satisfactory performance of the buildings. In literature review, design engineers need to conduct a time history analysis for such buildings which involves a full record of an existed seismic excitation as an external load. The full record of seismic load would be set at the base of the structure and then the equation of motion solved to conduct the dynamic responses such as acceleration, velocity and displacement responses. To study the complete elastic response of the system linear time history is required, in this method, the seismic response of the system is determined at each time increment under a selected ground acceleration.

Time history analysis is one of the most powerful dynamics analysis that gives the full response of the structure during and after the dynamic loads has been applied, unlike response spectrum analysis which only gives the peak seismic responses.

Time history analysis is conducted to evaluate the seismic performance of a structure under dynamic loading of an excited ground motion (Wilkinson \& Hiley, 2006). Time History analysis is a technique used to determine the dynamic response of a structure under the action of any time dependent loads (Musil, Sivý, Chlebo, \& Prokop, 2017). 
Time history analysis is used to determine the seismic response of a structure under dynamic loading of representative earthquake (Wilkinson \& Hiley, 2006). Time history analysis is a step by step analysis of the dynamic response of a structure to a specified loading that may vary with time (Patil, \& Kumbhar, 2013). The ordinary differential equations are widely used in many engineering and applied science applications because most of the physical laws are simply formulated as diff erential equations. However, the most common use of differential equations is in the study of complex control systems. In the disciplinary of civil engineering differential equations are formulated in such a way that best describes the vibration of the building structures called "equation of motion". The equations of motion are formed in terms of second order differential equations. Therefore, the solutions of these equations are very complex and require high computational efforts, for linear time-invariant systems with time dependent loads (Wang, 1998). However, one can get benefit of the solution algorithms developed for first order equations (Mendoza Zabala, 1996). Converting the governing differential equations to a set of first order equations is the standard approach for most disciplines (Mendoza Zabala, 1996). The generalized displacements and velocities of nodal degrees of freedom as global state variables were used for this purpose (Simeonov, Sivaselvan, \& Reinhorn, 2000). The previous studies showed that SSR method is an excellent way for the analysis of complicated control systems (Barham. Brwa, \& Twana 2020). SSR method could be used to get the full response of a linear dynamic system could be obtained at any given instant of time during the ground acceleration (Luenberger, 1964).

\section{Assumptions for Linearity}

- The total mass of each story is lumped at the center of each story.

- Story beams are infinitely rigid in comparison to story columns.

- No changes in the nature of the boundary conditions during and after the analysis

- The system is elastic linear time invariant (ELTI) and material nonlinearity is not considered.

\section{Research Method}

State space representative is utilized to analyze mathematical model of physical systems, SSR works efficiently with systems that can reduce their orders to set of coupled first order differential equations. Therefore, systems that have order differential equations would be converted into an equivalent first order ODEs. The motion of a structural building is governed by $2^{\text {nd }}$ order differential equation

The below equation is a free vibration equation of motion for un-damped MDOF systems (Javed, Aftab, Qasim, \& Sattar, 2008). Based on the assumption made in section (II), the differential equation is written in such way, so that the inertia forces $(M \ddot{x})$ together with the dissipative forces $(D \dot{x})$ and elasticity forces $(K x)$ are equilibrating the external forces (Çakmak, 1996).

$$
M \ddot{x}+D \dot{x}+K x=0
$$

This is a governing homogeneous second-order differential equation. To describe the behavior of the structural building subjected to ground acceleration equation 1 changed to.

$$
M \ddot{x}(t)+D \dot{x}(t)+K x(t)=-M \lambda \ddot{x}_{g}(t)
$$

Where; $\mathrm{M}$ is the mass matrix, $\mathrm{D}$ is the damping matrix that approximates the energy dissipation due to structural materials only, $\mathrm{K}$ is the stiffness matrix of the structure, $\mathrm{x}, \dot{x}$ and $\ddot{x}$ are time varying vectors of floor displacement, velocity and acceleration respectively. $\lambda$ is a vector of ones, if there is any external forces or ground acceleration. $\lambda$ is zero, if there is no external force or ground accelerations, 
and $\ddot{x}_{g}$ is a vector of the acceleration due to selected earthquake. $\ddot{x}_{g}$ is a time dependent load. The damping matrix is assumed to be proportional to the mass and stiffness matrices.

$$
\ddot{x}(t)=-M^{-1} D \dot{x}(t)-M^{-1} K x(t)-\lambda \ddot{x}_{g}(t)
$$

\subsection{Inputs, Outputs and States of the System}

System inputs: The notation $u(t)$ is column vector used to represent the system's input signals. For undamped system subjected to earthquake loads there is only one input signal which is ground acceleration $\ddot{x}_{\mathrm{g}}$, therefore the force is defined as

$$
\ddot{\mathrm{x}}_{\mathrm{g}}(\mathrm{t})=\mathrm{u}(t)
$$

State equation: it's a minimal number of first order differential equations utilized in state space representation. Number of sets depends on the order of the differential equation which is used to mathematically describe the behavior of dynamical system. The vector notations are used to collect the entire state variables in sets of a state vectors. (Bathe, 2006). The concept of the state of a nonlinear dynamic system, refers to a minimum set of variables, known as state variables, which fully describe the system and its response to any given set of inputs.

To fully describe the state of the system during the entire ground excitation, two states of the system at initial condition $(t=0)$ is required. The state variables for frame structures systems are the position $z_{1}(0)$ and velocities $z_{2}(0)$, and the initial acceleration as the third state it can be obtained from the other two states.

$$
\ddot{x}(t)=-M^{-1} D \dot{x}(t)-M^{-1} K x(t)-\lambda \ddot{x}_{g}(t)
$$

Let, the first state variable be the displacement and the second state variable be velocity

$\mathrm{z}_{1}(t)=\mathrm{x}(t)$ Displacement

$$
\mathrm{z}_{2}(t)=\dot{\mathrm{x}}(t) \text { Velocity }
$$

To find $z_{1}$ knowledge of $z_{2}$ is required, on the other hand, to find $z_{2}$ knowledge of $z_{1}$ is required this system is called coupled system. The state-space representation can be thought of as a partial reduction of the equation list to a set of simultaneous differential equations rather than to a single higher order differential equation [8].

Then, based on equ. 6 and 7 the two first order differential equations should be written to represent the states above $\dot{z}_{1}(t)$ and $\dot{z}_{2}(t)$.

$$
\begin{aligned}
& \dot{z}_{1}(t)=\dot{x}(t) \\
& \dot{\mathrm{z}}_{2}(t)=\ddot{\mathrm{x}}(t)
\end{aligned}
$$

The following are two coupled first order differential equations replacing the second order differential equation. Equ.10 is combination of equ.7 and 8. Substitute equations 4, 6 and 7 in equ.5 to obtain equ.11.

$$
\begin{gathered}
\dot{z}_{1}(t)=z_{2}(t) \\
\dot{z}_{2}(t)=-M^{-1} D z_{2}(t)-M^{-1} K z_{1}(t)-\lambda \mu(t)
\end{gathered}
$$


Matrix form of equ.10 and 11.

$$
\left|\begin{array}{c}
\dot{\mathrm{z}}_{1}(\mathrm{t}) \\
\dot{\mathrm{z}}_{2}(\mathrm{t})
\end{array}\right|=\left|\begin{array}{cc}
\mathrm{I} & 0 \\
-\mathrm{M}^{-1} \mathrm{D} & -\mathrm{M}^{-1} \mathrm{~K}
\end{array}\right| \begin{gathered}
\mathrm{z}_{2}(\mathrm{t}) \\
\mathrm{z}_{1}(\mathrm{t})
\end{gathered}|+| \begin{gathered}
0 \\
-\lambda
\end{gathered} \mid \mu(\mathrm{t})
$$

Matrix form of state space representation for LTI dynamic systems subjected to time variant load is:

$$
\begin{gathered}
\mathbf{Z}(t)=\left|\begin{array}{c}
z_{1}(t) \\
z_{2}(t)
\end{array}\right| \text { and } \dot{\mathbf{Z}}(t)=\left|\begin{array}{c}
\dot{z}_{1}(t) \\
\dot{z}_{2}(t)
\end{array}\right| \\
\left|\begin{array}{l}
\dot{z}_{1}(t) \\
\dot{z}_{2}(t)
\end{array}\right|=\left|\begin{array}{cc}
0 & I \\
-M^{-1} K & -M^{-1} D
\end{array}\right|\left|\begin{array}{c}
z_{1}(t) \\
z_{2}(t)
\end{array}\right|+\left|\begin{array}{c}
0 \\
-\lambda
\end{array}\right| \mu(t)
\end{gathered}
$$

The state vector $\mathrm{Z}(\mathrm{t})$ contains enough information to completely summarize the past behavior of the system, and therefore the future behavior is controlled by a simple first-order differential equation [7].

For linear time history analysis, material nonlinearity is not considered during the whole analysis process, so the mass, stiffness, and damping matrices do not vary with time. If the dynamical system is linear time-invariant and has finite-dimensional, then the differential equation may be written in matrix form (Li, \& Pileggi, 2003).

\subsection{The Following is SSR for an LTI System}

$$
\begin{aligned}
& \dot{Z}(t)=A Z(t)+B u(t) \text { State Equation } \\
& y(t)=C Z(t)+D u(t) \text { Output Equation }
\end{aligned}
$$

System Output: The notation $y(t)$ is used to represent the system's output signals. In the case of structural response analysis there are three different output signals which are displacement $z_{1}(t)$, velocity $\dot{z}_{1}(t)$ and acceleration $\dot{z}_{2}(t)$.

\subsection{The State Space Matrices are as Follows:}

Matrix A: is the system matrix, of the size (2n, 2n).

$$
\mathrm{A}=\left[\begin{array}{cc}
0 & \mathrm{I} \\
-\mathrm{M}^{-1} \mathrm{~K} & -\mathrm{M}^{-1} \mathrm{D}
\end{array}\right]_{2 n * 2 n}
$$

Where, $n$ is number of degrees of freedom of the structure.

Matrix B: is the control matrix, of the size $(2 n, m)$. Through the B matrix the system input affects the state change.

$$
\mathrm{B}=\left[\begin{array}{r}
0 \\
-\lambda
\end{array}\right]_{2 n * m}
$$

Where, $\mathrm{m}$ is number of inputs, here the only input is ground acceleration, so $m=1$

Matrix C: Is the output matrix, of the size (n, 2n) and determines the relationship between the system state and the system output. 


$$
C=\left[\begin{array}{cc}
1 & 0 \\
0 & 1 \\
-M^{-1} K & -M^{-1} D
\end{array}\right]_{3 n \cdot 6 n}
$$

Matrix D: Is the feed-forward matrix, of the size (n, 1). D matrix allows the system input directly affects the system output,

$$
D=\left[\begin{array}{c}
0 \\
0 \\
-\lambda
\end{array}\right]_{3 n \cdot 1}
$$

\subsection{Matrix Form for MIMO State Space System}

$$
\left[\begin{array}{l}
y(t) \\
\dot{y}(t) \\
\ddot{y}(t)
\end{array}\right]=\left[\begin{array}{cc}
1 & 0 \\
0 & 1 \\
-M^{-1} K & -M^{-1} D
\end{array}\right]\left|\begin{array}{l}
z_{1}(t) \\
z_{2}(t)
\end{array}\right|+\left[\begin{array}{c}
0 \\
0 \\
-\lambda
\end{array}\right] \mu(t)
$$

Although, state space representative is a time domain approach which can be used to analysis multiinput multi-output (MIMO) systems. However, the structure utilized in this paper is uncontrolled by dampers, therefore the only input signal is a ground acceleration which is mean there is a single input. The Outputs of this dynamic system could be any of the following responses displacement, velocity, and acceleration, or all of them.

For more explicit results a separate output equation was defined for each response to convert the system to single-input / single-output (SISO) system.

1- Displacement

$$
\begin{aligned}
& \text { Let } y=x \\
& C=\left[\begin{array}{ll}
\mathrm{I} & 0
\end{array}\right]_{n * 2 n} \text { and } D=[0]_{n * 1} \\
& y(t)=\left[\begin{array}{ll}
\mathrm{I} & 0
\end{array}\right]\left|\begin{array}{|l}
z_{1}(t) \\
z_{2}(t)
\end{array}\right|+[0] \mu(t)
\end{aligned}
$$

2- Velocity

$$
\begin{aligned}
& \text { Let } y=\dot{x} \\
& \qquad=\left[\begin{array}{ll}
0 & \mathrm{I}
\end{array}\right]_{n * 2 n} \text { and } D=[0]_{n * 1} \\
& \dot{y}(t)=\left[\begin{array}{ll}
0 & \mathrm{I}
\end{array}\right]\left|\begin{array}{|l}
z_{1}(t) \\
z_{2}(t)
\end{array}\right|+[0] \mu(t)
\end{aligned}
$$

3- Acceleration:

Let $y=\ddot{x}$

$C=\left[\begin{array}{ll}-M^{-1} K & -M^{-1} D\end{array}\right]_{n * 2 n}$

and $D=[-\lambda]_{n * 1}$

$$
\ddot{y}(t)=\left[\begin{array}{ll}
-M^{-1} K & -M^{-1} D
\end{array}\right]\left|\begin{array}{l}
z_{1}(t) \\
z_{2}(t)
\end{array}\right|+[-\lambda] \mu(t)
$$




\section{MATLAB Code Used to Solve Linear Time Invariant System}

ss command is used to convert dynamic system models to state-space model form this operation is called state-space representation. ("Create state-space model, convert to state-space model MATLAB ss," n.d.) [("State-space model - MATLAB," n.d.].

$$
\text { sys }=\operatorname{ss}(A, B, C, D)
$$

("Simulate time response of dynamic system to arbitrary inputs - MATLAB 1sim,”)

$$
[y, t]=\operatorname{lsim}(\operatorname{sys}, u g, t)
$$

\section{Case Study}

A mathematical model of five story one bay shear frame was created. The height of each story is 3 meters and bay width of 4 meter. The mathematical model includes the elements of the entire structure for which physical and material properties can be assigned. Those members are modelled by elastic line elements. The basic concept for this analysis is to idealize the structural model as a soft columnrigid beam structure with total story mass lumped at each floor. The analysis was based on the assumptions that the system is elastic linear time-invariant (ELTI) system and material nonlinearity is not considered. The aim of this case study was to conduct a linear time history analysis and investigated the structural response to observe the accuracy of SSR method. The 1940 El-Centro earthquake time histories have been used in the study.

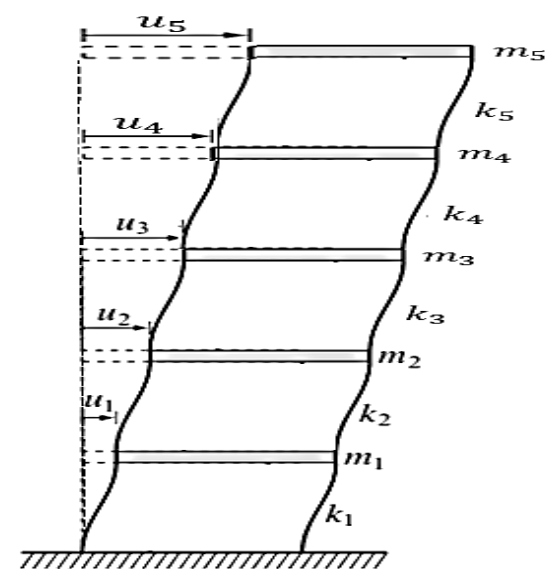

Figure 1: Mathematical model

\subsection{Physical and Material Properties of Mathematical Model}

- The floor plates were designed as rigid members (floor $\mathrm{I}=\infty$ ) for two purposes.

1. Reduce the total number of degrees of freedom from four degree to two degrees

2. Reduce the analysis time.

- Seismic weight of the building has been determined using the modal analysis. The total mass is assumed to be equal at each story and lumped at the center of the story level (Saatcioglu, \& Humar 2003; Waghmare, Pajgade, \& Kanhe, 2012). 
Table 1: Mass Matrix of Five Story Structure $\left(\mathrm{KN} \cdot \mathrm{s}^{\wedge} 2 / \mathrm{m}\right)$

\begin{tabular}{|r|r|r|r|r|}
\hline \multicolumn{1}{|r|}{$M_{1}$} & 0 & 0 & 0 & 0 \\
\hline 0 & $M_{2}$ & 0 & 0 & 0 \\
\hline 0 & 0 & $M_{3}$ & 0 & 0 \\
\hline 0 & 0 & 0 & $M_{4}$ & 0 \\
\hline 0 & 0 & 0 & 0 & $M_{5}$ \\
\hline
\end{tabular}

- The stiffness for each column is calculated independently as follows.

$$
K=\text { number of clumns } \times \frac{12 E I_{\text {column }}}{h^{3}}
$$

Then, the stiffness for all columns is combined to determine the global stiffness matrix of the system.

Table 2: Stiffness Matrix of Five Story Structure $\left(\mathrm{KN} / \mathrm{m}^{\wedge} 2\right)$

\begin{tabular}{|r|c|c|c|r|}
\hline$k_{1}+k_{2}$ & $-k_{2}$ & 0 & 0 & 0 \\
\hline$-k_{2}$ & $k_{2}+k_{3}$ & $-k_{3}$ & 0 & 0 \\
\hline 0 & $-k_{3}$ & $k_{3}+k_{4}$ & $-k_{4}$ & 0 \\
\hline 0 & 0 & $-k_{4}$ & $k_{4}+k_{5}$ & $-k_{5}$ \\
\hline 0 & 0 & 0 & $-k_{5}$ & $k_{5}$ \\
\hline
\end{tabular}

Figure 2 shows the full-time history record of El-Centro 1940 earthquake that was used in the analysis. The displacement, velocity, and acceleration responses for $5^{\text {th }}$ floor due to selected ground motion are plotted in fig. 3,8 , and 10 respectively.

The results showed that booth method has the same displacement along the height of the building with slightly difference at the $3^{\text {rd }}$ node for the right direction $(\max )$ and at $5^{\text {th }}$ node for left direction $(\min )$ as shown in figures 4 and 5 .

Table 5 and 6 tabulates the results of max. and min. displacements, in these tables its clearly shown that the maximum absolute difference between the two methods, which is only $3.35 \mathrm{~mm}$ at the roof in left side direction, while the maximum absolute difference in story drift ratio is 0.0016 at the same location as the difference in displacement as tabulated in tables 7 and 8.

The story drift and drift ratio for each software obtained as the difference between the maximum displacement of two adjacent story's which can be expressed as a percentage of the story height.

$$
\text { Story drift }{ }_{i i}=\Delta_{i i}-\Delta_{i}
$$


Furthermore table 9 and 10 shows max. absolute relative velocity, and max. absolute relative acceleration results respectively. Fig. 9 and 11 illustrates per story max absolute relative velocity, and max. absolute relative acceleration respectively.

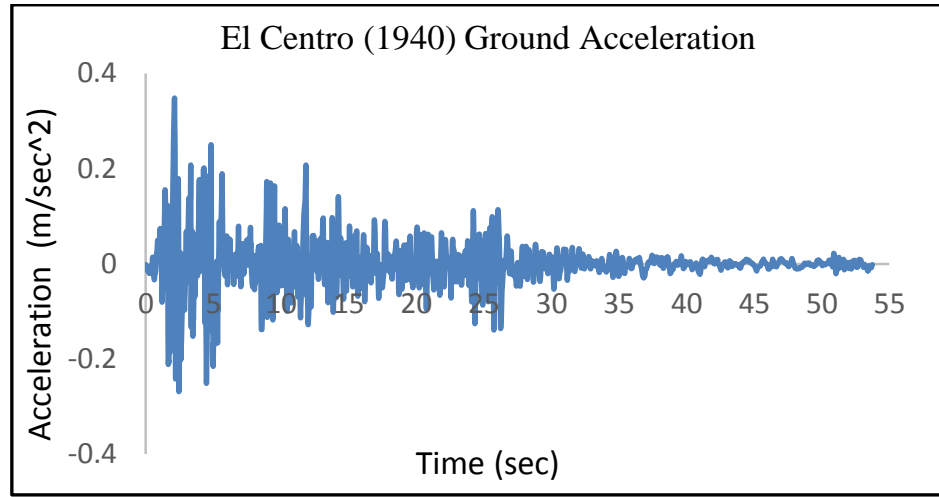

Figure 2: El-Centro ground motion record, 1940

\section{Results}

Table 3: Values for Omega by Mode ( $\mathrm{rad} / \mathrm{sec})$

\begin{tabular}{|l|l|l|l|l|}
\hline 3.94 & 0 & 0 & 0 & 3.94 \\
\hline 0 & 11.51 & 0 & 0 & 0 \\
\hline 0 & 0 & 18.15 & 0 & 0 \\
\hline 0 & 0 & 0 & 23.31 & 0 \\
\hline 0 & 0 & 0 & 0 & 26.59 \\
\hline
\end{tabular}

Table 4: Values for Time Period by Mode (sec)

\begin{tabular}{|l|l|l|l|l|}
\hline 1.59 & 0 & 0 & 0 & 0 \\
\hline 0 & 0.55 & 0 & 0 & 0 \\
\hline 0 & 0 & 0.35 & 0 & 0 \\
\hline 0 & 0 & 0 & 0.27 & 0 \\
\hline 0 & 0 & 0 & 0 & 0.24 \\
\hline
\end{tabular}

Maximum absolute displacement response with the peak value of $0.154 \mathrm{~m}$ occurs at floor five at time $6.18 \mathrm{sec}$, as shown in fig. 3 . 


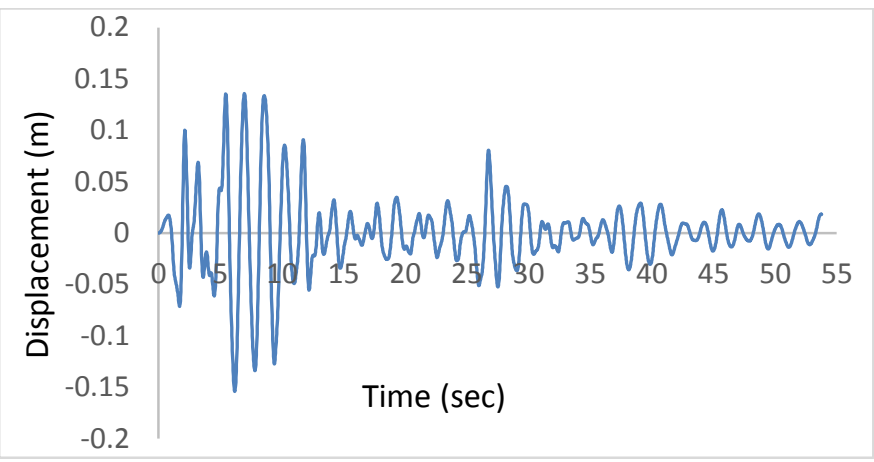

Figure 3: Response Spectra Displacement at $5^{\text {th }}$ floor

Table 5: Max. Displacements at each story

\begin{tabular}{|l|l|l|}
\hline \multicolumn{3}{|l|}{ Max. displacement (mm) } \\
\hline Story & MATLAB & ETABS \\
\hline St. 5 & 135.60 & 135.28 \\
\hline St. 4 & 124.24 & 125.18 \\
\hline St. 3 & 103.41 & 100.75 \\
\hline St. 2 & 75.79 & 76.48 \\
\hline St. 1 & 42.62 & 43.45 \\
\hline
\end{tabular}

Table 6: Min. Displacements at each story

\begin{tabular}{|c|c|c|}
\hline \multicolumn{3}{|c|}{ Max. displacement (mm) } \\
\hline Story & MATLAB & ETABS \\
\hline St. 5 & -154.19 & -150.84 \\
\hline St. 4 & -140.78 & -142.32 \\
\hline St. 3 & -118.02 & -119.38 \\
\hline St. 2 & -87.49 & -89.34 \\
\hline St. 1 & -47.37 & -46.16 \\
\hline
\end{tabular}




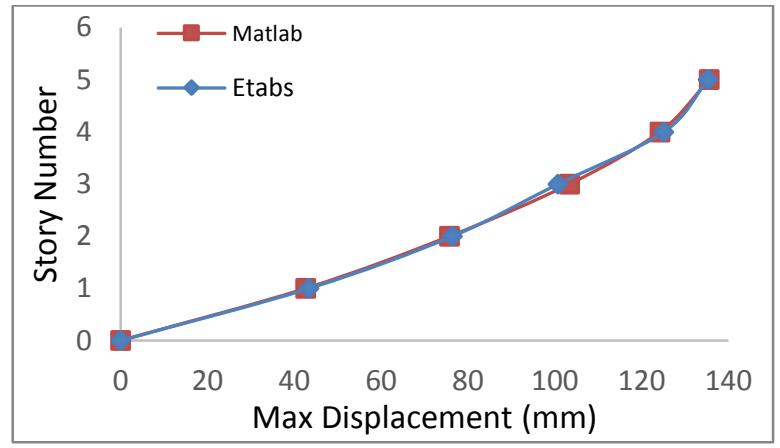

Figure 4: Max. Relative Displacements

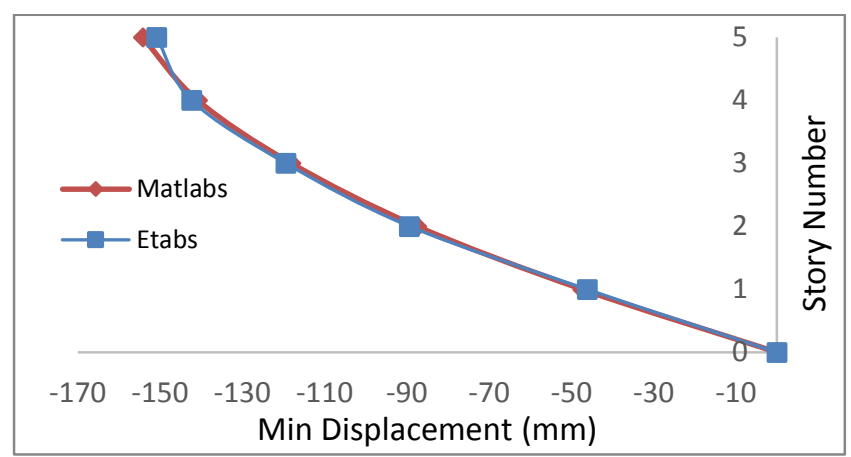

Figure 5: Min. Relative Displacements

Table 7: Max-Inter story drift Ratio

\begin{tabular}{|l|l|l|l|l|}
\hline \multirow{2}{*}{ Story } & \multicolumn{2}{|l|}{ Inter story drifts $(\mathrm{mm})$} & \multicolumn{2}{l|}{ Drift Ratio } \\
\cline { 2 - 5 } & MATLAB & ETABS & MATLAB & ETABS \\
\hline St. 5 & 0.011 & 0.010 & 0.00379 & 0.00337 \\
\hline St. 4 & 0.021 & 0.024 & 0.00694 & 0.00815 \\
\hline St. 3 & 0.028 & 0.024 & 0.00921 & 0.00809 \\
\hline St. 2 & 0.033 & 0.033 & 0.01106 & 0.01101 \\
\hline St. 1 & 0.043 & 0.043 & 0.01421 & 0.01448 \\
\hline
\end{tabular}

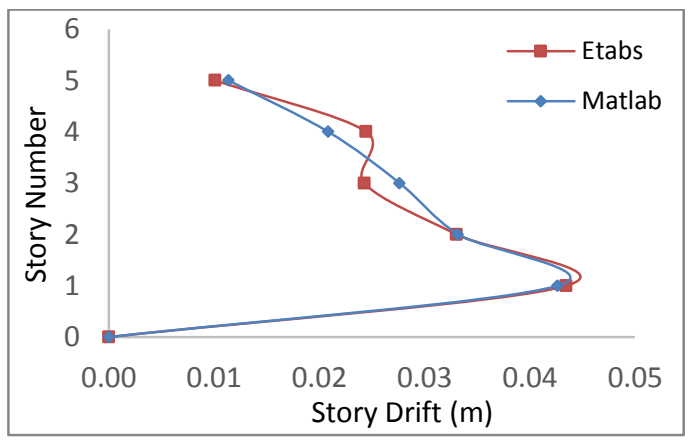

Figure 6: Max. Inter-Story Drift Ratios vs Story Numbers 
Table 8: Min-Inter story drifts (mm)

\begin{tabular}{|l|l|l|l|l|}
\hline \multirow{2}{*}{ Story } & \multicolumn{3}{|l|}{ Inter story drifts (mm) } & \multicolumn{2}{l|}{ Drift Ratio } \\
\cline { 2 - 5 } & MATLAB & ETABS & MATLAB & ETABS \\
\hline St. 5 & -0.013 & -0.009 & -0.0044 & -0.0028 \\
\hline St. 4 & -0.023 & -0.023 & -0.0076 & -0.0076 \\
\hline St. 3 & -0.031 & -0.030 & -0.0101 & -0.0100 \\
\hline St. 2 & -0.040 & -0.043 & -0.0133 & -0.0143 \\
\hline St. 1 & -0.047 & -0.046 & -0.0158 & -0.0153 \\
\hline
\end{tabular}

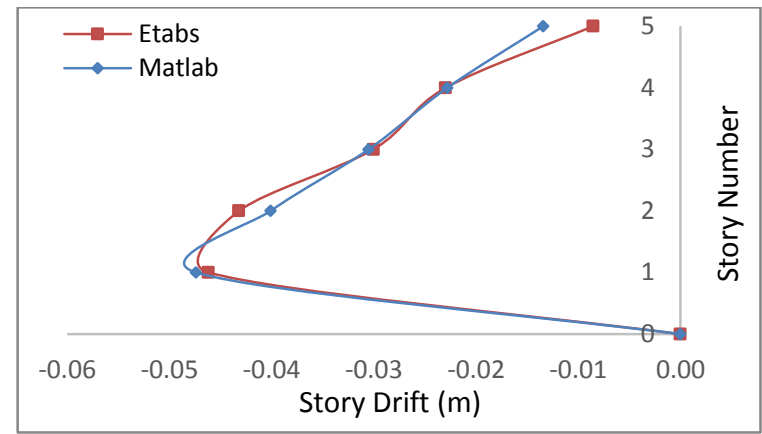

Figure 7: Min. Inter-Story Drift Ratios vs Story Numbers

Maximum absolute velocity response with the peak value of $0.676 \mathrm{~m} / \mathrm{sec}$ occurs at floor number five at 5.68 sec., as shown in fig. 8.

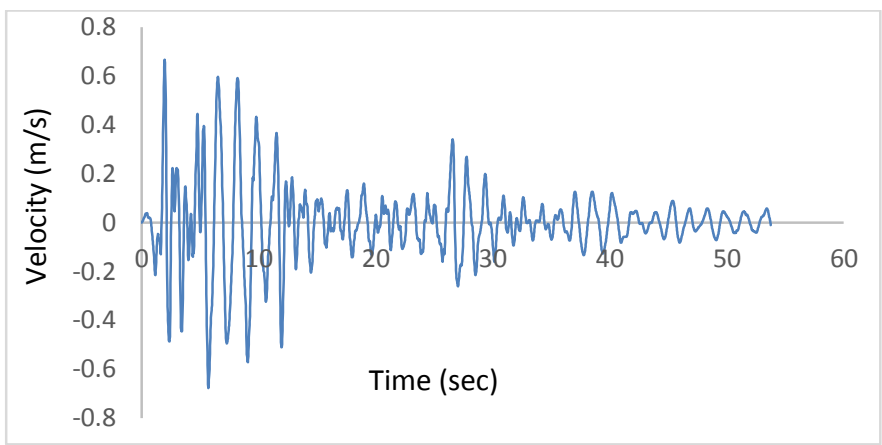

Figure 8: Response Spectra Velocity at $5^{\text {th }}$ Floor 
Table 9: Max. Absolute Relative Velocity at each Story

\begin{tabular}{|l|l|l|}
\hline \multicolumn{3}{|l|}{ Max. Absolute Relative Velocity (m/s) } \\
\hline Story & MATLAB & ETABS \\
\hline St. 5 & 0.67 & 0.65 \\
\hline St. 4 & 0.59 & 0.61 \\
\hline St. 3 & 0.54 & 0.56 \\
\hline St. 2 & 0.43 & 0.45 \\
\hline St. 1 & 0.25 & 0.32 \\
\hline
\end{tabular}

Table 9 shows clearly that the velocity decreases down relatively with the story height. The velocity is greatest at the base which is $0.25 \mathrm{~m} / \mathrm{s}$ and $0.32 \mathrm{~m} / \mathrm{s}$ for each software, then it decreases to minimum at roof.

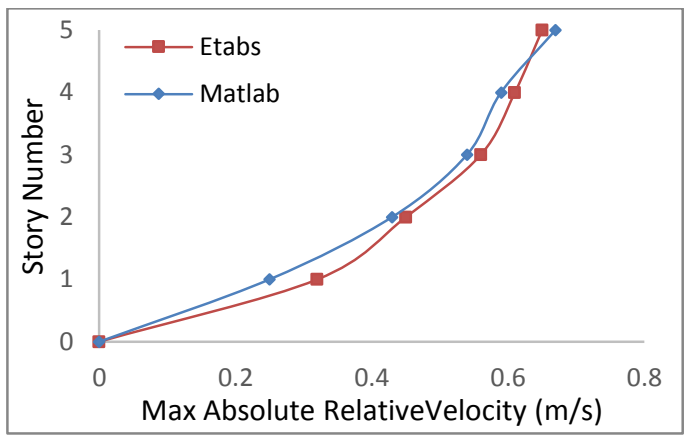

Figure 9: Max. Absolute Relative Velocity vs Story Height

Maximum absolute acceleration response with the peak value of $6.97 \mathrm{~m} / \mathrm{s}^{2}$ occurs at story number five at $2.12 \mathrm{sec}$, as shown in fig. 10.

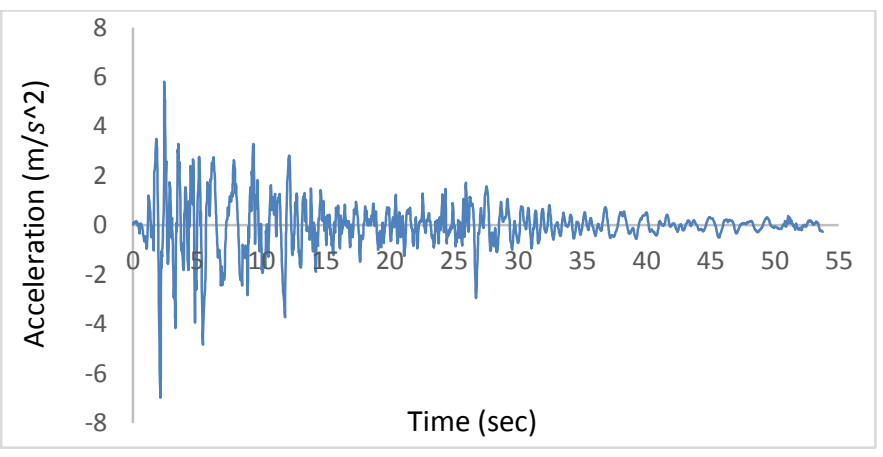

Figure 10: Response Spectra Acceleration at each story

Fig. 10 shows the response of the system in terms of time histories (amplitudes versus time), when the base of the structure has been shaken by seismic waves it causes the vibration in the structure, this vibration transfer to the whole of the building. The acceleration increases from first floor to the 
maximum acceleration at the roof. Both ETABS software and MATLAB showed the same action with slight difference in magnitudes refer to fig. 11.

From the analytical result, it's been observed that the mathematical model used in this paper behaved exactly as a real structure. Furthermore, the structural behavior was also compared with the results obtained in (Waghmare, Pajgade, \& Kanhe, 2012) and (Dyke, Spencer, Sain, \& Carlson, 1996) and the comparison was accepted. Figure 2 and 8 also showed that the building acceleration was identical with the exact ground acceleration used in the analysis.

Table 10: Max. Absolute Relative Acceleration at each Story

\begin{tabular}{|l|l|l|}
\hline \multicolumn{2}{|l|}{ Max. Absolute Relative Acceleration (m/s^2) } \\
\hline Story & MATLAB & ETABS \\
\hline St. 5 & 6.97 & 6.38 \\
\hline St. 4 & 5.49 & 5.49 \\
\hline St. 3 & 4.37 & 4.66 \\
\hline St. 2 & 5.5 & 5.8 \\
\hline St. 1 & 5.48 & 5.96 \\
\hline
\end{tabular}

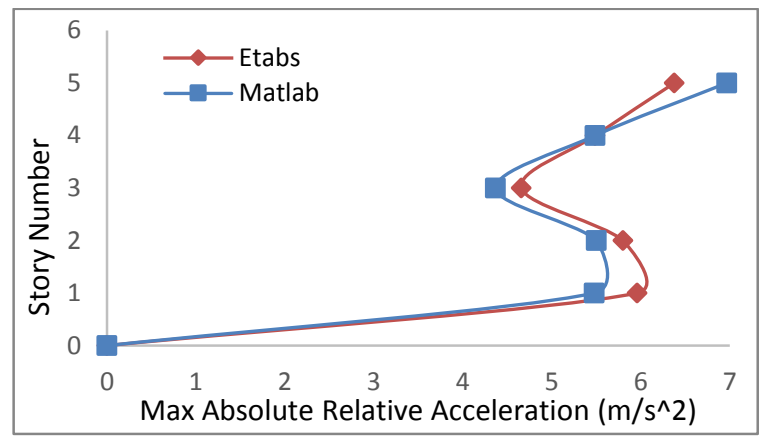

Figure 11: Max. Absolute Relative Acceleration vs Story Height

\section{Conclusion}

In this study a mathematical model is created for a regular five story one-bay and one-way building modeled in MATLAB software. An optimized analysis methodology utilizing SSR Method has been approached for linear time history analysis. The objectives of this study were to compute the structural response to a given ground acceleration "El Centro 1940". The results showed a significant similarity in comparison with ETABS software.

The resulted also conducted that the SSR is an excellent way for full record time history analysis of complicated control systems. The following are advantages of SSR method. 
- The results of SSR method is significantly accepted in comparison with world widely trusted software ETABS.

- The results showed a significant similarity in comparison with ETABS software. The maximum absolute difference of displacement and story drift ratio was $3.35 \mathrm{~mm}$ and 0.0016 was obtained at the roof of third and fifth story respectively.

- SSR method could be utilized to obtain a full description of a dynamic system at any given instant of time during and after the ground acceleration.

- SSR method is utilized to obtain all structural responses from one analysis run.

- SSR models work excellently with MATLAB, very small-time steps could be used as it's not affected by the computational costs.

- As SSR method could be run in MATLAB software, working with results is more friendly than ETABS software

- SSR method is applied to linear time invariant with multi input-multi output systems.

\section{References}

Barham, H., Brwa, A.S., \& Twana, A. H. (2020). Time History Analysis of frame structures systems by state space representation (SSR) method. EPU Journal, 10(1-7),

Bathe, K. J. (2006). Finite element procedures. Klaus-Jurgen Bathe.

Çakmak, A. Ş. (1996). Dynamics of structures: Theory and applications to earthquake engineering. Prentice Hall.

Create state-space model, convert to state-space model - MATLAB ss. (n.d.). Retrieved from https://www.mathworks.com/help/control/ref/ss.html

Dyke, S. J., Spencer Jr, B. F., Sain, M. K., \& Carlson, J. D. (1996). Modeling and control of magnetorheological dampers for seismic response reduction. Smart Materials and Structures, 5(5), 565.

Hangos, K. M., Lakner, R., \& Gerzson, M. (2001). Fuzzy Control Systems. Intelligent Control Systems: An Introduction with Examples, 191-226

Javed, M., Aftab, H., Qasim, M., \& Sattar, M. (2008). RLC circuit response and analysis (using state space method). IJCSNS International Journal of Computer Science and Network Security, $8(4), 48-54$.

Li, P., \& Pileggi, L. T. (2003, June). NORM: compact model order reduction of weakly nonlinear systems. In Proceedings of the 40th annual Design Automation Conference (pp. 472-477).

Luenberger, D. G. (1964). Observing the state of a linear system. IEEE Transactions on Military Electronics, 8(2), 74-80.

Mendoza, Z. J. L. (1996). State-space formulation for structure dynamics (Doctoral dissertation, Massachusetts Institute of Technology).

Musil, M., Sivý, M., Chlebo, O., \& Prokop, O. (2017). Seismic response of elevated liquid storage tanks. $16^{\text {th }}$ Conference on Applied Mathematics APLIMAT 2017, 1(9), 978-1-5108-3698-3

Patil, A. S., \& Kumbhar, P. D. (2013). Time history analysis of multistoried RCC buildings for different seismic intensities. International Journal of Structural and Civil Engineering Research, 2(3), 194-201.

Saatcioglu, M., \& Humar, J. (2003). Dynamic analysis of buildings for earthquake-resistant design. Canadian Journal of Civil Engineering, 30(2), 338-359.

Simeonov, V. K., Sivaselvan, M. V., \& Reinhorn, A. M. (2000). Nonlinear analysis of structural frame systems by the state- space approach. Computer-Aided Civil and Infrastructure Engineering, 15(2), 76-89.

Simulate time response of dynamic system to arbitraryinputs - MATLAB lsim. (n.d.). Retrieved from https://www.mathworks.com/help/control/ref/lsim.html 
Waghmare, P. B., Pajgade, P. S., \& Kanhe, N. M. (2012). Response spectrum analysis of a shear frame structure by using MATLAB. International Journal of Applied Science and Engineering Research, 1(1), 1-10.

Wang, C. Y. (1998). Dynamic simulation tool for seismic analysis (Doctoral dissertation, Massachusetts Institute of Technology).

Wilkinson, S. M., \& Hiley, R. A. (2006). A non-linear response history model for the seismic analysis of high-rise framed buildings. Computers \& Structures, 84(5-6), 318-329. 